\title{
Partnership Through Co-creation: Lessons Learnt at the University of Adelaide
}

\author{
Catherine Snelling ${ }^{a}$, Beth R Loveys ${ }^{b}$, Sophie Karanicolas ${ }^{a}$, Nathan James Schofield ${ }^{b}$, William \\ Carlson-Jones ${ }^{a}$, Joanne Weissgerber ${ }^{a}$, Ruby Edmonds ${ }^{a}$, and Jenny Ngu $^{a}$ \\ a Adelaide Dental School, University of Adelaide, Australia \\ b School of Agriculture, Food and Wine, University of Adelaide, Australia
}

Contact: $\underline{\text { catherine.snelling@adelaide.edu.au }}$

\section{ABSTRACT}

This paper describes three exemplars of practice inspired by emerging evidence that student-staff partnerships have the potential to significantly enhance many areas of higher education. Students and academics at the University of Adelaide have successfully implemented this collaborative approach across a range of learning and teaching contexts. The Design Thinking Framework, developed by the Hasso Plattner Institute of Design at Stanford University, was utilised at a faculty, program, and course level to frame each of the exemplars, due to its implicit approach to creativity, collaborative development, and achievement of solutions. The iterative nature of the framework facilitated a review cycle for continuous improvement in each Students-asPartners' initiative. Analysing the outcomes of each exemplar has identified common hallmarks of successful partnership, and these indicators have the potential to contribute to the growing body of evidence that defines best practice in this pedagogy.

\section{KEYWORDS}

Students as Partners, student-staff partnership, co-creation, higher education, design thinking

Contemporary research shows growing evidence that when students and teachers work together in an authentic partnership, there are tangible benefits for all (Mercer-Mapstone et al., 2017; Curran, 2017; Cook-Sather, Bovill, \& Felten, 2014). These benefits include positive impacts on student engagement, increased motivation for the learning process by students and staff, as well as enhanced inclusiveness in teaching practices. Healey, Flint, and Harrington (2014) present a series of case studies in the Higher Education Academy's seminal publication 
"Engagement through partnership: Students as partners in learning and teaching in higher education" that demonstrate the multi-disciplinary and expansive context where Students-asPartners (SaP) projects have flourished. Inspired by this work in the co-creation space within a Students-as-Partners framework, academics and students at the University of Adelaide have trialled this collaborative approach across a range of learning and teaching contexts. The university has acknowledged the need for a greater emphasis on student partnerships, but in particular is embracing the co-creation aspect as a strategic direction in learning and teaching activities.

The three exemplars of practice described in this paper demonstrate authentic approaches to co-creation and were chosen due to their diverse partnership settings (Healey, 2014). In each exemplar, curriculum development activities were viewed through the lens of each partner-the student and the teacher-to develop a shared vision to cater to the needs of all participants. This paper reflects on the lessons learnt from each of these co-creation activities and considers the implications for future practice at the University of Adelaide.

The Design Thinking Framework (DTF), developed by the Hasso Plattner Institute of Design at Stanford University (Plattner, Meinel, \& Leifer, 2015), provided a scaffold that underpinned each exemplar. Originally devised by designers, this solution-based, rather than problem-based process, has been successfully applied across a wide variety of disciplines including education (Razzouk \& Shute, 2012). The DTF was chosen due to its human-centred process which challenges participants' beliefs and assumptions and nurtures an empathetic approach to designing solutions with the end-user in mind. In addition, Razzouk and Shute (2012) identified the importance of students learning to creatively solve problems through design thinking as ideal preparation for real-work practice. These characteristics make it well aligned with the philosophy of the Students-as-Partners pedagogy as it is critical to involve the end users at tall stages of any project. "Co-creation and design thinking often goes hand in hand since design thinking needs stakeholders to test the prototypes and co-creation involves them in early stages of the process" (Ghent University, n.d.). Using this scalable methodology allowed a meaningful comparison of the structure and outcomes of each co-created exemplar. The DTF has five distinct stages:

- Empathise: developing a shared understanding of the problem from both a student and teacher perspective;

- Define: defining the shared purpose to a core problem;

- Ideate: finding and exploring possible solutions to the core problem born from diverse standpoints;

- Prototype: developing a first draft of what the co-created solution might look like, sharing with others and refining based on their feedback; and

- Test: end-users testing the co-created solution in an authentic context and providing feedback on whether the core problem has been solved or managed.

These non-linear stages facilitate a collaborative approach to solving complex issues and generating shared outcomes for effective results. Each stage is grounded in critical reflection, allowing collaborators the agility to review, evaluate, and revise progressive outcomes. More importantly, the DTF provides opportunity for students to be "directly engaged in information 
gathering, knowledge generation, communication and presentation" (Harvard University Teaching and Learning Lab, n.d.).

A guiding question was embedded at each stage of the planning to clarify each DTF stage, drive the collaborative activities, and help design the co-created exemplars (Fig. 1).

Figure 1. Guiding questions for each stage of Design Thinking Framework adapted from https://dschool.stanford.edu/

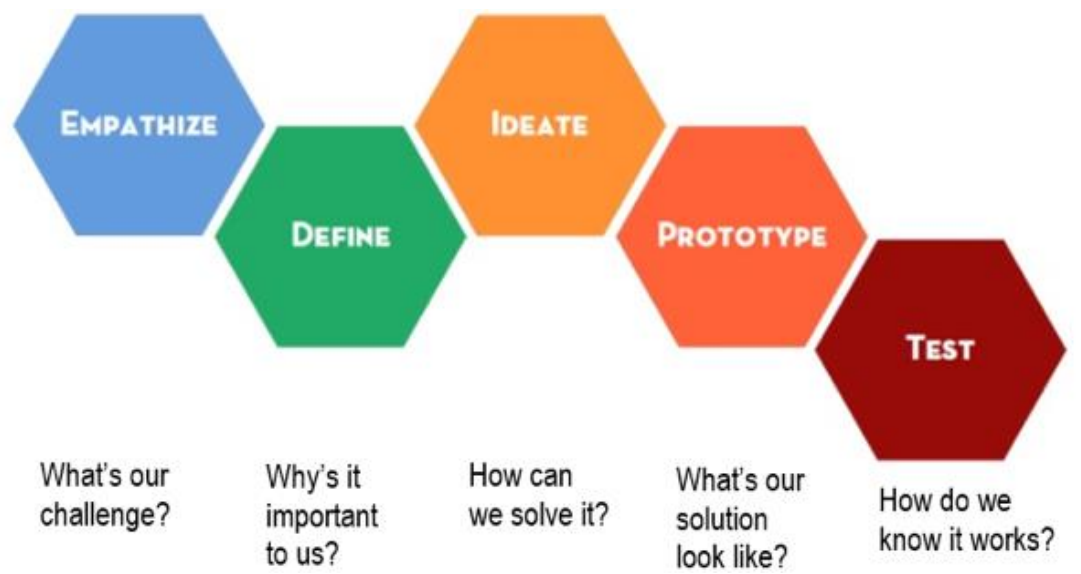

Working within the context of a SaP model (Healey et al., 2014) and employing the DTF, students and staff collaborated in three distinct pilot studies, described in this paper as exemplars 1, 2, and 3. Healey (2014) also described partnership as being possible at different organisational and operational levels from co-creation of learning activities to planning strategic organisational directions (Fig. 2).

Figure 2. Setting and levels of student partnership (Healey, 2014)

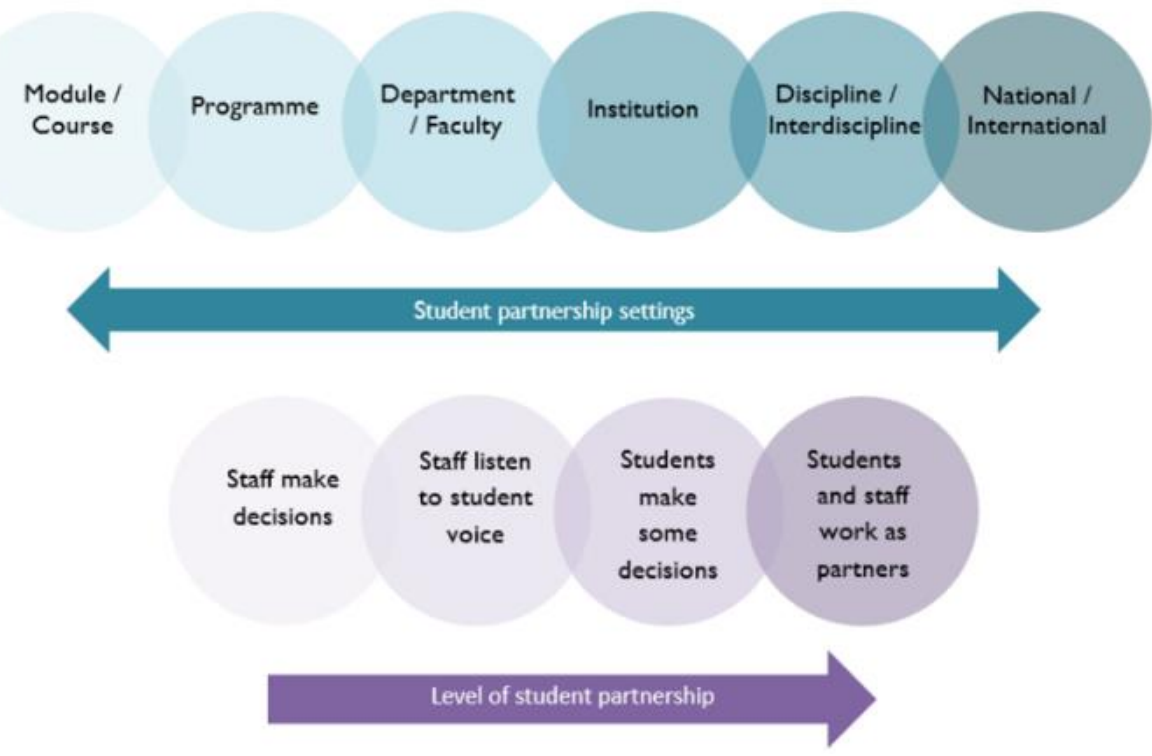


Exemplar 1 correlates with the department/faculty level, whilst exemplars 2 and 3 are situated within the module/course setting. This SaP model also specifies that the level of student involvement should be considered as part of a continuum ranging from "simple" consultation (staff decision-making) to a "sophisticated" level of partnership (where students and staff work as partners). Exploring the nature of a genuine partnership facilitates an understanding of how true co-creation activities flourish. True partnerships have been succinctly defined by Matthews (2017) as "respectful, mutually beneficial learning partnerships where students and staff work together on all aspects of educational endeavours" (p. 1). Being willing to provide and receive candid feedback in the joint planning process and having an open sensitivity to one another's needs formed a crucial part of the trusting environment that characterises each of the co-creation exemplars.

\section{EXEMPLARS OF PRACTICE}

\section{Exemplar 1: A workshop to co-create principles for inquiry-based learning}

Exemplar 1 (E1) is a co-created faculty-wide initiative to develop good practice principles for inquiry-based learning. The Small Group Discovery Experience (SGDE), a mandated pedagogical initiative at the University of Adelaide established in 2014, is an inquirybased learning approach that involves students discovering new knowledge under expert guidance. It was regarded as a way to strengthen links between teaching and research and to foster an inquiry-based learning culture; however, it was implemented with minimal capacity building or staff development. By 2016, there was a wide level of dissatisfaction from students (evidenced by formal course evaluations), as well as teachers (evidenced by an annual staff survey), with how the pedagogy was being implemented across the university. A Faculty of Health Science Learning and Teaching Advancement Grant brought a project team together that included academics from each of the five schools within the faculty. Each academic personally invited students and staff from their area who had been identified as being engaged or disengaged in inquiry-based learning projects. There was a healthy response that culminated in 32 health science students and 16 staff selected to collaborate in a -analysis workshop. All participants were informed that the collective outcomes would contribute to a strategic approach to remedy dissatisfaction with SGDE across the university. In the workshop, groups of two students and one teacher compiled collective lists of their positive and negative experiences of SGDE in the first phase of the DTF, the empathy phase, which involves asking, "What's our challenge?" What became evident at this point was the importance of allowing time for both students and staff to become comfortable working in what was for many an unfamiliar (and potentially disconcerting) equitable partnership. It also became clear that it was important for students to outnumber teachers in each group in order to counter the perceived power imbalance. Some teachers initially felt that they would be compelled to defend any expected criticism, whilst students needed to be empowered to share their opinions in a safe environment. Each member of the groups were first asked to share an example of an SGDE experience. This was a non-threatening and straightforward task to which all students and teachers could equally contribute. From these discussions, it was identified that SGDE was being implemented across the university with varying degrees of success and with little evidence of core principles. Once this was established, the groups undertook a real-time online 
activity to formulate a common purpose as part of the second phase of DTF, the define phase, where participants work to answer, "Why is this project important to us?" Students were required to undertake an SGDE as part of their studies, and staff were required to run these activities, but the collective definition became that "it's important for students and staff to agree on the value and structure of SGDE activities, so everyone benefits from the experience."

The next stage of the co-creation process was the ideation stage, where participants collaborate to answer, "How can we solve it?" Each group brainstormed a list of "good practice" SGDE principles and then agreed on their top four, mindful that the DTF process is focussed on solutions that benefit the end-user. In the case of SGDE, it could be argued that the end-users are not only students, but also staff who design and implement the activities. The value of using the DTF approach was evident at this point as it became necessary to revisit the definition and purpose of the challenge several times to ensure the ideations were appropriate. Eventually, the top four ideas from each group were uploaded onto an online repository. These data were collated during a meal break (catering appears to be critical to co-creation success) and then presented to all 48 participants to analyse their aggregated responses to draft "best SGDE practice principles," which comprised the prototyping phase guided by the question, "What's our solution look like?" After several revisions to the prototype, based on group feedback, these co-created principles (see Figure 3) were ready for the final phase of the DTF: the test phase, which asks, "How do we know it works?"

Fig 3: Prototype of Exemplar 1's Best Practice Principles for SGDE (Snelling, 2016)

\section{Co-created Best Practice Principles for SGDE}
Always include:
- Industry insight - 'real' perspectives
- Authentic assessment
- Real world application
- Putting theory into practice
- Small groups $(<10)$
- Interaction between staff \& students
- Making it 'novel' - not just another lecture or tute

\section{Never include:}

- No structure or clearly defined outcomes

- Groups being too large

- No assessment - no incentive to participate

- Poorly structured group activities

- Mundane 'meaningless' activities

- Replication of tutorial - didn't feel 'special'

- No practical application to discipline

- "Why are we doing this?"

These best practice principles were peer-reviewed by the university's Small Group Discovery Experience Community of Practice before workshops were run for designers and facilitators of SGDE initiatives across the faculty. Positive feedback from workshop participants in the formal evaluation included comments such as "it was good to know that the recommendations and guidelines that were being given had come from both students and other teaching colleagues." 


\section{Lessons learnt by staff}

Academics who attended the training analysis workshop reported that once they overcame their initial concerns about dealing with criticism about their teaching, they found the co-creation experience to be very positive. They also found that working with students from other courses was an effective way to receive feedback about SGDE design in a more objective context. They enjoyed receiving a range of good ideas to incorporate into their own classes in an informal and collegial atmosphere. Many of the staff at the workshop reported that they were impressed and motivated by the authentic "buy-in" by students to contribute to the quality of their learning experiences, with one teacher commenting: "it's far better to work directly with students on course design, than to try and predict what I think will be effective," and another saying that "it was great to look at SGDE through a different lens, it was very refreshing."

\section{Lessons learnt by students}

In a post-workshop focus group (run by students), students strongly indicated that they found the co-creation experience a lot less intimidating than they initially imagined. Having more students than staff in each group and being assigned to specific groups were important factors. Several students had concerns before the workshop that they would be working with teachers from their own courses and felt uncertain they could give honest opinions and feedback. So, collaborating with teachers from different courses helped them to give more candid views on their SGDE experiences. Several students commented how positive it was seeing first-hand how teachers were committed to enhancing course design, and how their contributions were actively sought and valued by staff. Formally recognising student input by providing a certificate of participation for their CVs was extremely well received-in fact, staff requested a similar acknowledgement.

\section{Exemplar 2: A workshop to co-design assessment tasks}

In Exemplar 2 (E2), undergraduate students and academics partnered to design assessment tasks for a new course in a science program. The co-creation workshop involved second- and third-year students and academic staff from plant science-related degrees within the Faculty of Sciences. The ratio of students to staff was greater (4:1), an important characteristic of successful co-creation, as was demonstrated in E1. Before participants arrived at the workshop, all participants completed an online survey which gave everyone an opportunity to formulate ideas regarding their opinions and experiences with learning and teaching in anticipation of the task ahead. This information was used to create an environment where all participant contribution was valued and where participants could collectively empathise and determine "what's our challenge?" Critical issues including "pros" and "cons" of assessment design, timing, and assessment type were discussed by participants in groups comprising one academic staff member and four students to define the problem and determine "why is it important to us?" Once the problem to be solved was established, the groups proceeded to ideate by designing assessment tasks that met the needs of both staff and students while achieving the learning outcomes in order to answer "how can we solve it?" After each smaller group had outlined their thoughts for the assessment task, these were then 
discussed as a larger group and synthesised to create the required assessment tasks, thus determining a prototype. A key outcome at this stage was that students and staff agreed that providing a diverse range of different assessment types would be beneficial to students and could be offered in a way as to not increase teacher workload. The assessment task choices developed were online quizzes, developing instructional videos for peers, traditional scientific reports, or oral presentations. The new course ran for the first time in 2017, and the enrolled students were aware that the assessment tasks had been designed by a process of co-creation. The inaugural student cohort were enthusiastic to complete the assessment for the first time in an authentic context, which represented the testing phase of DTFFeedback from the first students enrolled in the course indicated that the co-creation workshop had resulted in student-centred assessment tasks that successfully addressed the learning outcomes. For example, on students commented: "the assignments are great and informative. The practical component was good!" (University of Adelaide 2017 Semester 2 Course Evaluation). The nonlinear nature of the DTF was utilized to revise the assessment task from 2017 to 2018. Students enrolled in the course in 2018 participated informally in refining the assessment task by giving feedback and making suggestions for improvement (test phase of DTF). This iterative approach to improving the co-created assessment was reflected in improvements to scores in response to the formal course evaluation question: "This course uses methods of assessment that help achieve its learning outcomes," which scored 6.8 out of 7 in 2017, increasing to 7 out of 7 in 2018.

\section{Lessons learnt by staff}

The pre-workshop survey provided a non-threatening forum for all participants to be involved in discussion. It was clear to staff that students were empathetic towards the impact that some assessment styles would have on staff, particularly with respect to time-intensive marking. Staff felt that students developed an understanding for the challenges associated with assessment design. Staff observed that it was important to provide guidelines or boundaries, otherwise there was a risk of the task becoming overwhelming. Staff felt that engaging with students in this way had the potential to improve assessment design. The potential challenges of using this approach for curriculum development are not necessarily linked to the use of the DTF, but an inherent problem in many Students-as-Partners initiatives: that already-engaged students volunteer to participate. This may skew the outcomes due to these highly-motivated students designing assessment tasks that appeal only to similar types of students (Alsford, 2012).

\section{Lessons learnt by students}

There were two important collective realisations in this workshop. Firstly, students were highly motivated about having input into the type of assessment tasks developed during the workshop. The responses to the pre-workshop survey were important to ensure all students started discussions on the same page. The potential impact of different assessment styles on teachers was also explored by the students. Over the course of the workshop, they developed a deep understanding of the factors that must be considered for curriculum and assessment to work for both students and teachers. The students felt that their input into curriculum design 
was highly valued, and there was also a strong sense of the degree of care and consideration practiced by teachers with the aim of improving the student experience. For example, a student participant remarked that "it was endearing to know that as students, we had a voice in the future of the course, and that the teachers involved cared about the ideas and opinions that we put forward." Similar experiences have been reported by Deeley and Bovill (2017) in a study of a student and staff partnership in assessment literacy.

\section{Exemplar 3: A co-creation team to address poor performance in a course topic}

Exemplar 3 (E3) focuses on the co-creation of flipped classroom resources for a subject in the Bachelor of Oral Health program with a consistent failure rate of $>20 \%$. In 2016 , students who had just completed the second-level subject were invited to provide the course coordinator with feedback on the challenges that they had faced when learning the troublesome topic of periodontology. A call for interested students was posted on the class Facebook page. All students who registered an interest were invited to attend a "coffee get together" to discuss the issues and the potential of being involved in a co-creation project team to improve the subject outcomes. E3 was guided by the outcomes of E1 and E2, promoting a greater student-to-teacher ratio in a co-creation team.

Of the seven students who attended the first meeting, five students volunteered their time over the summer break to work on this co-creation project with the aim of improving the learning outcomes of the periodontology topic. Consequently, three of the five students made this co-creation activity the focus of their final-year capstone project.

The project began with three informal coffee meetings between the subject teacher and the five student volunteers. The environment for these meetings was purposefully structured to be informal, creating a friendly, trusting, and supportive environment to foster empathy and encourage participants to consider "what's our challenge?" The timing of these meetings was strategically scheduled for the post-assessment period, which provided students with the freedom to raise their issues without any stress or anxiety associated with exam time. The team clearly described the challenges that students faced, which primarily was the need to integrate knowledge of very complex concepts into clinical applications. Students openly discussed the need to have these concepts broken down into "bite-sized" chunks of information that could be easily digested before they could link them together and subsequently apply them to real-world contexts. The co-creation team were now in the position to clearly define why this topic was important to them; for example; if they wanted to provide evidence-based care to their patients they needed to feel confident that they understood the core concepts of Periodontology.

Ideas were shared, and collaborative discussions resulted in a strategy for the future delivery of this topic. The students decided that this content-heavy subject was best delivered using a flipped classroom approach, and they took on the responsibility of designing the preclass activities that would help to simplify the content. The teacher's role was to further develop these key concepts from the pre-class activities through application to real-word problem-solving scenarios in face-to-face class time. Students decided that short interactive videos were likely to be the most engaging pre-class activities. They proceeded to design 
storyboards for each of the three pre-class activities, which were then reviewed by the teacher for content accuracy.

The first prototype was developed as an "explain everything" video to cover the introductory topic. Students used this first video to provide a review of underpinning concepts before introducing the more complex concepts using Light Board technology. A Light Board video expert was invited to provide guidance on how to use this tool in a pedagogically sound way. The videos formed the next two pre-class activity prototypes, refined by the experience of producing the first video in a peer-to-peer instruction format. This new approach proved to be extremely effective during the testing phase. For the first time in eight years, the failure rate was less than $5 \%$. What was even more striking was that almost $60 \%$ of the students' performance fell well within the distinction to high distinction range. Focus-group discussions highlighted the fact that students felt that their peers were able to explain complex concepts better than experts. For example, one student commented: "Sometimes teachers know the content so well that it is hard for them to relay it to a student in an easy-to-understand way" (2017, focus group comment). Another focus-participant shared the following: "The third years have done a great job! It's so good to give future/current students help in this course from a student perspective. . . . at times it feels like there are quite some hurdles in the way!" (2017, focus group comment).

\section{Lessons learnt by staff}

Although the staff involved with this project were acknowledged for their long-standing student-centred approach in their teaching, the learning issues highlighted by students in initial project meetings were remarkably enlightening. No formal course survey would have been able to articulate the problems with this topic in such a succinct and authentic manner. It was crucial during the initial phases that the teacher nurtured a genuinely collaborative environment through the social coffee meetings that proved instrumental in removing any power issues. It was also critical that the teacher was an active listener who was able to objectively consider the issues and support the ideas raised by the students. It is doubtful that the learning resources that resulted would have been of such high quality if the teacher or students worked independently of each other. Furthermore, evaluation of these resources from student cohort using them as part of the periodontology topic far exceeded the expectations of co-creators in the project team. The was evident in a range of feedback mechanisms, but most significantly through comments in formal course evaluations and the strong interest from students keen to be involved in future co-creation projects. The teacher observed high-level knowledge and skill development in the student members of the project team, surpassing the standard expected of a final-year undergraduate Bachelor of Oral Health student.

Co-created initiatives like E3 require a considerable time commitment from teachers and students alike at all stages of the project. In this particular case, this included building the students' capacity to storyboard a video script as well as to constructively align learning activities to learning outcomes. Finding suitable times to meet for planning, capacity-building, and resource development was often difficult due to student rosters. An unexpected challenge was the students being self-conscious during video recording sessions when the teacher was present. This was alleviated by students being on their own during most of the recording times. 
The teacher then reviewed the video, leading to an increase in time required for feedback and post-production. On balance this time investment was validated by the positive outcomes for student learning.

Perhaps the most difficult challenge in E3 was the perception of other academics that these student-produced learning resources did not come from experts in the field and therefore should not be considered as a reliable learning resource. Cook-Sather and colleagues (2014) acknowledged this commonly held view when stating that "student-faculty partnerships in pedagogical explorations is troublesome because it is at once counterintuitive for many faculty and contradictory to norms in higher education" (p. 89). To counter this negative view, the co-creation team invited a specialist in the field of periodontology to review the studentgenerated learning resources, which further increased the amount of feedback and validation. Despite this, resistance from some academics remained. This factor may always be a challenge in any Students-as-Partners initiative.

\section{Lessons learnt by students}

Exemplar 3 reflected how difficult it is for teachers to articulate complex concepts about a topic that students find genuinely challenging. This partnership model allowed students the opportunity to define the learning issues about a difficult topic, then design learning resources to address these specific problems. These concepts formed the key components of the cocreated video content. The supportive nature of this partnership allowed filming to take place with a measured amount of guidance from the teacher but with enough space for the students to create in a relaxed environment. The student content was verified by the teacher, which validated the student contribution and helped to build their confidence. Although students working on the videos were aware of the project being a learning resource for their peers, the appreciation and outstanding improvements in the performance of their peers exceeded expectations. Having a diverse student production team meant that everyone contributed their strengths in different areas (e.g., content design, video editing, professionalism, illustration), which allowed the video creation process to flow.

\section{DISCUSSION}

Based on the collective outcomes of the three exemplars, building empathy in the cocreation teams is a key factor for success. Healey, Flint, and Harrington (2016) found that developing a sense of belonging increases chances of student success and state that "developing partnership learning communities among faculty and students can strengthen and sustain engagement" (p. 6). Each exemplar had an initial team-building activity to nurture partnership and a shared sense of purpose. Characteristically, each was a low-stakes, nonthreatening exercise where participants could all make an equal contribution, based on their personal experiences - in other words, there were no "right answers" that could create a sense of inequity between students and teachers.

Building on the initial activities was important for the co-creation teams in each exemplar to define the purpose of the projects and why a positive outcome would benefit both students and teachers. Torres and Schaffer (2000) describe the importance of "equal voice; shared responsibilities; shared vision" (p. 102) in Students-as-Partners initiatives. Embedding 
these principles in the exemplars led to a shared understanding of purpose by all members of the team. It is evident in each exemplar that this occurred by agreement on a set of bestpractice approaches to inquiry-based learning (E1), identifying the critical aspects of assessment (E2), and determining learning issues for a "troublesome" course (E3). By defining the key intention (or core problem) of each co-created project, participants could proceed with a shared vision.

The ideation stage of the DTF could be considered the most innovative for both staff and students. This is where ideas can develop and grow and the perspectives of both students and teachers can be synthesised to create a shared outcome. This stage is often where teachers have to reconsider their traditional role as gatekeepers of curricula (Bovill, 2013). In the three exemplars, students were active participants in developing ideas and finding solutions for enhanced course design (E1), assessment tasks (E2), and learning resources (E3). Bovill and colleagues (2016) see this as a key factor in successful co-creation. Ideation requires creativity, confidence, and trust in teacher and student partnerships. Co-creation of ideas and concepts becomes authentic when the motivation and diverse experience each person brings to the table is valued and applied (Bovill, 2013). Having said this, it remains a challenge for teachers to seemingly divest some of their control to students, whilst students are often reluctant to assert their ideas. This necessary cultural shift in the SaP approach is well documented in the literature (Mercer-Mapstone et al., 2017; Matthews, 2016; Healey et al., 2014). All three exemplars strove to address this challenge through careful attention to the first two stages of the DTF.

The prototype stage involves developing solutions to core problems or issues that can be tested. The identified challenge and purpose in each exemplar led to the development of prototypes to solve these problems. For example, E1 developed good practice principles for SGDE course design from both a student and teacher perspective. In E2, co-creation explored critical issues including "pros" and "cons" of assessment design, timing, and assessment type that contributed to a more student-centred assessment strategy. The team in E3 co-developed a solution to address the problem of why is there such a high failure rate for this topic?

The Design Thinking Educators Toolkit (2014) explains that "building prototypes means making ideas tangible, learning while building them and sharing them with other people.... you can receive a direct response and learn how to further improve and refine an idea" (p. 57). This is an important aspect of the prototypes developed in each co-created exemplar, where each group had deeper conversations to refine their prototypes before the testing could begin.

Testing the co-created prototype is a critical step in the DTF process as it determines whether the prototype solved the problem defined in stage two. The three exemplars presented in this paper span various organisational levels but are all grounded in the learning and teaching space rather than institutional policy. A useful approach to testing the value of cocreated products has been proposed by Dollinger, Lodge, and Coates (2018), where the products are viewed through a "value co-creation" lens, allowing evaluation of which type of co-creation activities provide the greatest benefit to both students and teachers. Value cocreation has its roots in consumer-driven market research, so this approach may seem to be in conflict within an educational paradigm. Matthews, Dwyer, Hine, and Turner (2018) considered this approach as potentially problematic for both students and teachers "because [the 
consumer model] reduced the learning and teaching experience to a transactional relationship" (p. 5). However, 21st century students are often referred to as consumers (Bunce, Baird, \& Jones, 2017), and it seems relevant that value co-creation theory would provide an appropriate analysis instrument. The testing of the prototypes in each exemplar took more than one form. It was underpinned by the consumer model approach as well as by identifying evidence of the student voice as described in Bovill and Bulley's (2011) ladder of participation. This combined approach provided a more holistic evaluation of the effectiveness of each prototype in a fitness-for-purpose co-created context. The best-practice principles (E1) underpinned a professional development workshop that was favourably evaluated as a fitness-for-purpose" model. A cohort of students enrolled in the new science course, the focus of E2, tested the cocreated assessment task as part of the course requirement. Students performed well in the assessment tasks, with the class average being $80 \%$. The learning resources generated in $\mathrm{E} 3$ were tested by the second-year student cohort, and their positive feedback and improved exam results verified the effectiveness of the co-created resources.

\section{IMPLICATIONS FOR FUTURE PRACTICE}

What has become clear from the outcomes of the three exemplars of co-created practice is an underpinning pedagogy of care (Hoffmann \& Stake, 1998). This begins from the empathy stage of the DTF. These student-staff partnerships nurtured collaborative and productive work environments through a genuinely caring approach and an authentic culture of equality. Contemporary educational research is recognising the importance of this factor for effective learning and collaboration. "Caring pedagogical work and caring subjectivities are nurtured and nurture attentiveness to creating time-spaces which foster dialogical co-creation of knowledges." (Motta \& Bennett, 2018, p. 636.)

Any co-creation initiative requires considerable skill to generate the right setting for the realisation of a shared outcome. The environment needs to foster fruitful discussion that is informal enough to establish empathy and trust, but with enough structure to harness the group's collective purpose. The DTF was an ideal scaffold due to its non-linear, iterative nature fostering regular reflection, review, and revision. Each exemplar had clear and shared objectives and was an authentic partnership in terms of equitable contribution and ownership. Students and teachers in each exemplar experienced a sense of achievement when they recognised how their individual contribution led to a positive outcome. This finding is echoed by a model of co-creation described by Bovill (2013), where active student participation led to "enhanced student responsibility for their learning, enhanced student performance and teachers' satisfaction" (pp. 23-24). Continuing to develop co-created projects and participating in national and international conferences such as the Australian National Students as Partners Roundtable (Enright, Matthews, Russell, \& Sherwood, 2018) and the International Students as Partners Institute (Marquis, Black, \& Healey, 2017) are important steps towards developing a broader conceptual framework.

\section{CONCLUSION}

The ever-increasing momentum for the Students-as-Partners paradigm to be considered an intrinsic part of higher education has been internationally acknowledged (Curran \& Millard, 
2016; Moore-Cherry, Healey, Nicholson, \& Andrews, 2016). At the same time, local initiatives where students and teachers have worked in authentic partnership have flourished (Loveys, McGrice, \& Snelling, 2018; Mars, 2009). This paper has demonstrated how three exemplars of what Mars (2009) calls grassroots practice using the Design Thinking Framework have generated successful and valuable outcomes at the faculty, program, and course level at the University of Adelaide. Based on this ethos of practice, other educators are encouraged to use the DTF model to frame their own co-creation initiatives to further assess its application in Students-as-Partners pedagogy.

\section{ACKNOWLEDGEMENTS}

We would like to acknowledge all workshop participants (staff and students) from the Faculty of Health Sciences and the Faculty of Sciences at the University of Adelaide for generously volunteering their time and enthusiasm to contribute to components of Exemplars 1 and 2, and for the students who so willingly contributed to the success of Exemplar 3.

\section{NOTES ON CONTRIBUTORS}

Catherine Snelling is an Associate Professor and Education Specialist at the Adelaide Dental School at the University of Adelaide, Australia.

Beth Loveys is a Senior Lecturer and Education Specialist in the School of Agriculture, Food and Wine at the University of Adelaide, Australia.

Sophie Karanicolas is an Associate Professor and an Education Specialist at the Adelaide Dental School at the University of Adelaide, Australia.

Nathan Schofield is a recent graduate of the Bachelor of Viticulture and Oenology in the School of Agriculture, Food and Wine at the University of Adelaide, Australia.

William Carlson-Jones is a recent graduate of the Bachelor of Oral Health Program at the University of Adelaide, Australia.

Joanne Weissgerber is a recent graduate of the Bachelor of Oral Health Program at the University of Adelaide, Australia.

Ruby Edmonds is a recent graduate of the Bachelor of Oral Health Program at the University of Adelaide, Australia.

Jenny Ngu is a recent graduate of the Bachelor of Oral Health Program at the University of Adelaide, Australia. 


\section{REFERENCES}

Alsford, S. (2012) An educational student forum: Working partnerships with students. Journal of Applied Research in Higher Education, 4(1), 186-202

https://doi.org/10.1108/17581181211273291

Bovill, C. (2013). Students and staff co-creating curricula: An example of good practice in higher education. In E. Dunne \& D. Owen (Eds.), The student engagement handbook: Practice in higher education (pp. 461-476). Bingley: Emerald.

Bovill, C., Cook-Sather, A., Felten, P., Millard, L., \& Moore-Cherry, N. (2016). Addressing potential challenges in co-creating learning and teaching: Overcoming resistance, navigating institutional norms and ensuring inclusivity in student-staff partnerships. Higher Education, 71(2), 195-208. https://doi.org/10.1007/s10734-015-9896-4

Bovill, C. \& Bulley, C. J. (2011). A model of active student participation in curriculum design: Exploring desirability and possibility. In C. Rust (Ed.), Improving Student Learning (18) Global theories and local practices: Institutional, disciplinary and cultural variations (pp. 176- 188). Oxford: The Oxford Centre for Staff and Learning Development.

Bunce, L., Baird, A., \& Jones, S. E. (2017). The student-as-consumer approach in higher education and its effects on academic performance. Studies in Higher Education, 42(11), 1958-1978. https://doi.org/10.1080/03075079.2015.1127908

Cook-Sather, A., Bovill, C., \& Felten, P. (2014). Engaging students as partners in learning and teaching: A guide for faculty. San Francisco: Jossey-Bass.

Curran, R. (2017). Students as partners-good for students, good for staff: A study on the impact of partnership working and how this translates to improved student-staff engagement. International Journal for Students as Partners, 1(2). https://doi.org/10.15173/ijsap.v1i2.3089

Curran, R., \& Millard, L. (2016). A partnership approach to developing student capacity to engage and staff capacity to be engaging: Opportunities for academic developers. International Journal for Academic Development, 21(1), 67-78. https://doi.org/10.1080/1360144X.2015.1120212

Deeley, S.J., \& Bovill, C. (2017). Staff student partnership in assessment: Enhancing assessment literacy through democratic practices. Assessment \& Evaluation in Higher Education, 42(3), 463-477. https//doi.org/10.1080/02602938.2015.1126551

Design Thinking Educator Toolkit (2014). Riverdale County School. Retrieved from https://designthinkingforeducators.com/toolkit/

Dollinger, M., Lodge, J., \& Coates, H. (2018). Co-creation in higher education: Towards a conceptual model. Journal of Marketing for Higher Education, 28(2), 210-231. https://doi.org/10.1080/08841241.2018.1466756

Enright, E., Matthews, K. E., Russell, S., \& Sherwood, C. (2018). National Students as Partners Roundtable Program. Retrieved from https://itali.uq.edu.au/about/projects/students-aspartners

Ghent University (n.d.). Cocreation course. Retrieved from https://www.ugent.be/thefoundry/en/services/cocreation.htm 
Harvard University Teaching and Learning Lab. (n.d.). Design thinking in education. Retrieved From http://tll.gse.harvard.edu/files/hgsetll/files/designthinkingeducation.pdf

Healey, M. (2014, February). Students as partners in learning and teaching in higher education. Workshop presented at University College Cork.

Healey, M., Flint, A., \& Harrington, K. (2014). Engagement through partnership: Students as partners in learning and teaching in higher education. York: HE Academy. Retrieved from https://www.heacademy.ac.uk/knowledge-hub/engagement-through-partnershipstudents partners-learning-and-teaching-higher

Healey, M., Flint, A., \& Harrington, K. (2016). Students as partners: Reflections on a conceptual model. Teaching \& Learning Inquiry, 4(2), 1-13. https://doi.org/10.20343/teachlearninqu.4.2.3

Hoffmann, F. L., \& Stake, J. E. (1998). Feminist pedagogy in theory and practice: An empirical investigation. National Women's Studies Association Journal (NWSA), 79-97. Retrieved from http://www.jstor.org/stable/4316555

Loveys, B. R., McGrice, H., \& Snelling, C. (2018). Students as partners: Developing a culture of co-creation at the University of Adelaide. Proceedings of Students, Transitions, Achievement, Retention and Success (STARS) Annual Conference, Auckland, New Zealand. Retrieved from https://unistars.org/papers/STARS2018/03E.pdf

Marquis, E., Black, C., \& Healey, M. (2017). Responding to the challenges of student-staff partnership: The reflections of participants at an international summer institute. Teaching in Higher Education, 22(6), 720-735. https://doi.org/10.1080/13562517.2017.1289510

Mars, M. M. (2009). Student entrepreneurs as agents of organizational change and social transformation: A grassroots leadership perspective. Journal of Change Management, 9(3), 339-357. https://doi.org/10.1080/14697010903125597

Matthews, K. (2016). Students as partners as the future of student engagement. Student Engagement in Higher Education Journal, 1(1). Retrieved from https://journals.studentengagement.org.uk/index.php/raise/issue/view/46/showToc

Matthews, K. (2017). Editorial: Five propositions for genuine students as partners practice. International Journal of Students as Partners 1(2): 1-9.

https://doi.org/10.15173/ijsap.v1i2.3315

Matthews, K. E., Dwyer, A., Hine, L., \& Turner, J. (2018). Conceptions of students as partners. Higher Education 76, 957-971. https://doi.org/10.1007/s10734-018-0257-y

Mercer-Mapstone, L., Dvorakova, S. L., Matthews, K., Abbot, S., Cheng, B., Felten, P., Knorr, K., Marquis, E., Shammas, R., \& Swaim, K. (2017). A systematic literature review of students as partners in higher education. International Journal for Students as Partners, 1(1). https://doi.org/10.15173/ijsap.v1i1.3119

Moore-Cherry, N., Healey, R., Nicholson, D. T., \& Andrews, W. (2016). Inclusive partnership: Enhancing student engagement in geography. Journal of Geography in Higher Education, 40(1), 84-103. https://doi.org/10.1080/03098265.2015.1066316

Motta, S. C., \& Bennett, A. (2018). Pedagogies of care, care-full epistemological practice and "other" caring subjectivities in enabling education. Teaching in Higher Education, 23(5), 631 646. https://doi.org/10.1080/13562517.2018.1465911

Plattner, H., Meinel, C., \& Leifer, L. (Eds.). (2015). Design thinking research: Making design 
thinking foundational. Springer.

Razzouk, R., \& Shute, V. (2012). What is design thinking and why is it important? Review of Educational Research, 82(3), 330-348. https://doi.org/10.3102/0034654312457429

Snelling, C. (2016). Final Report: Developing teacher capacity to design engaging and effective SGDE to enhance student learning in health sciences courses. University of Adelaide Learning and Teaching Development Grant.

Torres, J., \& Schaffer, J. (2000). Benchmarks for campus/community partnerships. Providence, RI: Campus Compact. 